\title{
Teknologi Informasi Sebagai Media Inovasi Pendidikan
}

\author{
Muhammad Mukhlis \\ Email: 1810111310008@mhs.ulm.ac.id \\ Program Studi Pendidikan Sejarah Fakultas Keguruan dan Ilmu Pendidikan \\ Universitas Lambung Mangkurat \\ Banjarmasin
}

\begin{abstract}
Abstrak
Inovasi (pembaharuan) terkait dengan invention dan discovery. Invention adalah suatu penemuan sesuatu yang benar benar baru, artinya hasil kreasi manusia. Penemuan sesuatu (benda) itu sebelumnya belum pernah ada, kemudian diadakan dengan bentuk kreasi baru. Inovasi adalah usaha menemukan benda yang baru dengan jalan melakukan kegiatan (usaha) baik invention dan discovery. Inovasi pendidikan adalah inovasi dalam bidang pendidikan atau inovasi untuk memecahkan masalah pendidikan.

Teknologi informasi telah menjadi fasihan pengalihan buku, guru dan sistem pengajaran yang sebelumnya konvensional. Penyebab Teknologi Informasi ilmu pengetahuan dalam tumbuh dan berkembang. Seiring dengan kemajuan teknologi yang mengglobal telah terpengaruh dalam segala aspek kehidupan baik di bidang ekonomi, politik, kebudayaan, seni dan bahkan di dunia pendidikan. Dalam dunia pendidikan, seorang guru harus berusaha mulai mengenalkan TI (Teknologi Informasi) terhadap anak didiknya, atau menggunakan TIK tesebut dalam proses belajar mengajar. Sebuah ide kreatif seorang guru sangat diperlukan untuk dapat mengubah situasi pembelajaran menjadi menarik dan efektif sekaligus mengajak siswa lebih aktif.
\end{abstract}

\section{PENDAHULUAN}

Kata "innovation" (bahasa Inggris) sering diterjemahkan segala hal yang baru atau pembaharuan (S. Wojowasito, 1972), tetapi ada yang menjadikan kata innovation menjadi kata Indonesia yaitu"inovasi". Inovasi kadang-kadang juga dipakai untuk menyatakan penemuan, karena hal yang baru itu hasil penemuan. Kata penemuan juga sering digunakan untuk menterjemahkan kata dari bahasa Inggris"discovery" dan"invention". Ada juga yang mengkaitkan antara pengertian inovasi dan modernisasi, karena keduanya membicarakan usaha pembaharuan. 
Inovasi pendidikan adalah inovasi dalam bidang pendidikan atau inovasi untuk memecahkan masalah pendidikan. Jadi, inovasi pendidikan adalah suatu ide, barang, metode yang dirasakan atau diamati sebagai hal yang baru bagi seseorang atau kelompok orang (masyarakat), baik berupa hasil intervensi (penemuan baru) atau discovery (baru ditemukan orang), yang digunakan untuk mencapai tujuan pendidikan atau memecahkan masalah pendidikan nasional.

Inovasi (pembaharuan) terkait dengan invention dan discovery. Invention adalah suatu penemuan sesuatu yang benar benar baru, artinya hasil kreasi manusia. Penemuan sesuatu (benda) itu sebelumnya belum pernah ada, kemudian diadakan dengan bentuk kreasi baru. Discovery adalah suatu penemuan (benda), yang benda itu sebenarnya telah ada sebelumnya, tetapi semua belum diketahui orang. Jadi, inovasi adalah usaha menemukan benda yang baru dengan jalan melakukan kegiatan (usaha) baik invention dan discovery.

\section{PERAN GURU SEBAGAI SEBUAH PROFESI}

Sebuah ide kreatif seorang guru sangat diperlukan untuk dapat mengubah situasi pembelajaran menjadi menarik dan efektif sekaligus mengajak siswa lebih aktif. Jika saat ini adalah era teknologi digital, ada kemungkinan ide pembelajaran yang kita kembangkan adalah lebih banyak berhubungan dengan teknologi digital karena secara mayoritas siswa akan lebih tertarik menghadapi sesuatu yang up to date. Dalam era globalisasi persoalanpersoalan yang muncul dalam pembelajaran salah satunya harus diantisipasi dengan inovasi-inovasi terhadap model pembelajaran atau media pembelajaran.

Seorang guru merupakan inovator yang pada dasarnya dituntut untuk memiliki kemampuan dalam meningkatkan mutu pendidikan melalui inovasi pembelajaran. Guru sebagai inovator pembelajaran mau tidak mau harus meningkatkan kemampuan diantaranya:

1. Teknologi yang merupakan kekuatan pendorong terhadap inovasi dan kesuksesan. Teknologi memang merupakan salah satu sumber inovasi, akan tetapi bukanlah satu-satunya. Kenyataannya saat ini banyak guru yang berupaya meraih keberhasilan untuk berinovasi.

2. Ada kreativitas yang tergantung gagasan-gagasan yang dimunculkan. Seorang inovator adalah orang yang berhasil mengambil peluang-peluang untuk mewujudkan gagasan-gagasan yang ada dan secara realita dapat dikembangkan.

Beberapa inovasi yang dapat dilakukan oleh seorang guru dalam mengubah situasi pembelajaran menjadi lebih menasrik dan efektif di era teknologi dan informasi ini adalah dengan memanfaatkan teknologi dan informasi yang ada, contohnya ketika guru pendidikan sejarah sedang dalam situasi belajar-mengajar dengan para siswanya, guru tidak hanya menggunakan buku sebagai media untuk mengajar para siswa, tetapi bisa juga dengan cara 
menampilkan video-video ilustrasi maupun rekaman asli peristiwa sejarah, agar para siswa lebih antusias dalam menyimak pembelajaran mereka. Tentu saja, tidak lupa untuk sambil berdiskusi antar guru dan siswa selama pembelajaran tersebut agar para siswa aktif dalam pembelajaran tersebut.

\section{GURU INDONESIA DAN TANTANGAN PROFESIONALISME}

Teknologi informasi telah menjadi fasihan pengalihan buku, guru dan sistem pengajaran yang sebelumnya konvensional. Penyebab Teknologi Informasi ilmu pengetahuan dalam tumbuh dan berkembang. Seiring dengan kemajuan teknologi yang mengglobal telah terpengaruh dalam segala aspek kehidupan baik di bidang ekonomi, politik, kebudayaan, seni dan bahkan di dunia pendidikan. Kemajuan teknologi adalah sesuatu yang tidak bisa kita hindari dalam kehidupan ini, karena kemajuan teknologi akan berjalan sesuai dengan kemajuan ilmu pengetahuan.

Dalam dunia pendidikan, seorang guru harus berusaha mulai mengenalkan TI (Teknologi Informasi) terhadap anak didiknya, atau menggunakan TIK tesebut dalam proses belajar mengajar. Proses inilah yang disebut sebagai Pembelajaran Berbasis Komputer.

Komunikasi sebagai media pendidikan dilakukan dengan menggunakan mediamedia komunikasi seperti telepon, komputer, internet, e-mail dan lain sebagainya. Interaksi antar guru dan siswa tidak hanya dilakukan melalui hubungan tatap muka dan juga dilakukan dengan menggunakan media-media tersebut. Guru dapat memberikan layanan tanpa harus berhadapan langsung dengan siswa. Demikian pula siswa dapat memperoleh informasi dalam lingkup yang luas dari berbagai sumber media cyber space atau ruang maya dengan menggunakan komputer atau internet.

Hal yang paling mutakhir adalah berkembangnya apa yang disebut "cyber teaching" atau pengajaran Maya, yaitu proses pembelajaran yang dilakukan dengan menggunakan internet. Istilah lain yang makin populer saat ini ialah e-learning yaitu satu model pembelajaran dengan menggunakan media Teknologi Komunikasi dan Informasi khususnya Internet. Menurut Rosenberg (2001), e-learning merupakan satu penggunaan

Tekonologi Internet dalam penyampaian pembelajaran dalam jangkauan luas yang berlandaskan tiga kriteria, yaitu:

1. E-learning merupakan jaringan dengan kemampuan untuk memperbaharui, menyimpan, mendistribusi dan membagi materi ajar atau Informasi,

2. Pengiriman sampai kepengguna terakhir melalui komputer dengan menggunakan teknologi Internet yang standar,

3. Memfokuskan pada pandangan yang paling luas tentang pembelajaran di balik paradigma pembelajaran tradisional.

Teknologi pembelajaran terus mengalami perkembangan seiring dengan perkembangan zaman. Dalam pelaksanaan pembelajaran sehari-hari kita sering jumpai 
adanya pemfaatan dari perkembangan Teknologi dalam dunia pendidikan, seperti yang sering dilakukan oleh guru atau dosen yaitu mengkombinasikan alat teknologi dalam peroses pembelajaran.

Internet merupakan salah satu alat komunikasi yang murah dimana memungkinkan terjadinya interaksi antara dua orang atau lebih. Kemampuan dan karakteristik internet memungkinkan terjadinya proses belajar mengajar jarak jauh (E-learning) menjadi lebih efektif dan efisien sehingga dapat diperoleh hasil yang maksimal.

Menurut Hamdani $(2011,248)$ media dapat di kelompokkan menjadi tiga jenis yaitu:

\section{Media Visual}

Media visual adalah media yang hanya dapat dilihat dengan menggunakan indra pengelihatan. Jenis media inilah yang sering di gunakan oleh para guru untuk membantu menyampaikan isi materi pelajaran. Media visual terdiri atas media yang tidak dapatkan diproyeksikan (non projected visual) dan media yang dapat di proyeksikan (project visual).

2. Media Audio

Media audio adalah media yang mengandung pesan dalam bentuk auditif (hanya dapat didengar) yang dapat merangsang pikiran, perasaan, perhatian, dan kemampuan para siswa untuk mempelajari bahan ajar. Program kaset suara dan program radio adalah bentuk media audio. Penggunaan media audio dalam pembelajaran pada umumnya untuk menyampaiakn materi pelajaran tentang mendengarkan.

3. Media audio visual

Sesuai dengan namanya media ini merupakan kombinasi audio dan visual atau biasa di sebut media pandang-dengar. Audio visual akan menjadikan penjayajian bahan ajar kepada siswa semakin lengkap dan optimal. Selain itu, media ini dalam batas-batas tertentu dapat juga menggantikan peran guru. Sebab, penyajian materi bisa diganti oleh media, dab guru bisa beralih menjadi fasiltatator belajar, yaitu memberikan kemudahan bagi para siswa untuk belajar. Contoh media audio visual, diantaranya program video atau televisi, video atau televisi intruksional, dan program slide suara (sound slide). 


\section{SIMPULAN}

Inovasi pendidikan adalah inovasi dalam bidang pendidikan atau inovasi untuk memecahkan masalah pendidikan. Jadi, inovasi pendidikan adalah suatu ide, barang, metode yang dirasakan atau diamati sebagai hal yang baru bagi seseorang atau kelompok orang (masyarakat), baik berupa hasil intervensi (penemuan baru) atau discovery (baru ditemukan orang), yang digunakan untuk mencapai tujuan pendidikan atau memecahkan masalah pendidikan nasional.

Dalam era perkembangan teknologi dan informasi saat ini, seorang guru harus memiliki pemikiran kreatif/inovatif dalam menciptakan situasi belajar yang menarik dan efektif sekaligus mengajak siswa untuk lebih aktif dalam proses pembelajaran. Perkembangan teknologi dan informasi memberikan dampak positif bagi guru dan siswa dalam memperoleh informasi mengenai suatu pembelajaran. Guru bisa menggunakan berbagai media dalam proses pembelajaran seperti, media visual, media audio, maupun audio-visual. Melalui media-media tersebut diharapkan guru bisa memberikan situasi belajar yang menarik dan efektif. 


\section{REFERENSI}

Anis, M. Z. A., Putro, H. P. N., Susanto, H., \& Hastuti, K. P. (2020). Historical Thinking Model in Achieving Cognitive Dimension of Indonesian History Learning. PalArch's Journal of Archaeology of Egypt/Egyptology, 17(7), 7894-7906.

Anis, M. Z. A., Susanto, H., \& Mardiani, F. (2021, February). Analysis of the Effectiveness of MPBH: The Mains of Mandai as a Saving Food in Banjarmasin Community. In The 2nd International Conference on Social Sciences Education (ICSSE 2020) (pp. 89-94). Atlantis Press.

Efendi, I., Prawitasari, M., \& Susanto, H. (2021). Implementasi Penilaian Pembelajaran Pada Kurikulum 2013 Mata Pelajaran Sejarah. Prabayaksa: Journal of History Education, 1(1), 21-25.

Susanto, H. (2020). Profesi Keguruan. Banjarmasin: FKIP Universitas Lambung Mangkurat.

Susanto, H., \& Akmal, H. (2018). Efektivitas Penggunaan Aplikasi Pembelajaran Berbasis Mobile Smartphone Sebagai Media Pengenalan Sejarah Lokal Masa Revolusi Fisik Di Kalimantan Selatan Pada Siswa Sekolah Menengah Atas. HISTORIA: Jurnal Program Studi Pendidikan Sejarah, 6(2), 197-206.

Susanto, H., Irmawati, I., Akmal, H., \& Abbas, E. W. (2021). Media Film Dokumenter Masuknya Islam Ke Nusantara dan Pengaruhnya Terhadap Keterampilan Berpikir Kritis Siswa. HISTORIA: Jurnal Program Studi Pendidikan Sejarah, 9(1).

https://dosen.ung.ac.id/Sulkifly/home/2020/10/6/konsep-dasar-inovasi-pendidikan.html

https://www.google.com/url?sa=t\&source=web\&rct=j\&url=https://publikasiilmiah.ums.acd /bitstream/handle/11617/3012/BUKU\%2520INOVASI\%2520PENDIDIKANLesson\%2520 Study.pdf\%3Fsequence\%3D1\%26isAllowed\%3Dy\%23: :text\%3DJadi\%252C\%2520inova si\%2520pendidikan\%2520adalah\%2520suatu,tujuan\%2520pendidikan $\% 2520$ atau $\% 2520 \mathrm{~m}$ emecahkan\%2520masalah\&ved=2ahUKEwjn4oSQ24rwAhUSeisKHVbOAUAQFjABegQ IAxAG\&usg=AOvVaw15CyUXrwkp9MZ28H0ALyJG\&cshid=1618849807988 (Buku Inovasi Pendidikan Lesson Study)

https://www.kompasiana.com/amp/kusuma_tyas/menjadi-guru-yang-kreatif-daninovatif_58d527a660afbd4115a718ac

https://www.google.com/url?sa=t\&source=web\&rct=j\&url=https://osf.io/umv4j/download/ \%3Fformat\%3Dpdf\&ved=2ahUKEwjj1sah44rwAhVXeX0KHS2QD10QFjACegQIBhAC \&usg=AOvVaw2BEHJLcWHNdF2UZ0GnI2NO (Artikel Fernando Bagus Caesar) 